\title{
Investigation of Commensal Escherichia coli Populations of Cormorant Hatchlings in the Absence of Anthropogenic Impacts in Remote Areas of West Mongolia
}

Muhammad Moman Khan 1(D), Rafal Kolenda ${ }^{2} \mathbb{D}$, Peter Schierack 1,3, Jörg Weinreich ${ }^{1}$, Stefan Rödiger 1,3 ${ }^{1 D}$, Jakob Schierack ${ }^{4}$, Michael Stubbe ${ }^{5}$, Davaa Lkhagvasuren ${ }^{6}$, Sebastian Guenther ${ }^{7}$ and Katharina Schaufler ${ }^{8, *}$

1 Institute of Biotechnology, Faculty of Environment and Natural Sciences, Brandenburg University of Technology Cottbus-Senftenberg, 01968 Senftenberg, Germany; khanm@b-tu.de (M.M.K.); peter.schierack@b-tu.de (P.S.); joerg.weinreich@b-tu.de (J.W.); stefan.roediger@b-tu.de (S.R.)

2 Department of Biochemistry and Molecular Biology, Faculty of Veterinary Medicine, University of Environmental and Life Sciences, 50-375 Wrocław, Poland; rafal.kolenda@upwr.edu.pl

3 Faculty of Health Sciences, Joint Faculty of the Brandenburg University of Technology Cottbus-Senftenberg, The Brandenburg Medical School Theodor Fontane and the University of Potsdam, 01968 Senftenberg, Germany

4 Lessing Gymnasium, 02977 Hoyerswerda, Germany; jakobschierack@gmail.com

5 Gesellschaft für Wildtier- und Jagdforschung e.V., 06099 Halle/Saale, Germany; stubbe@zoologie.uni-halle.de

6 Department of Biology, School of Arts and Sciences, National University of Mongolia, Ulaanbaatar 14200, Mongolia; lkhagvasuren@num.edu.mn

check for updates

Citation: Khan, M.M.; Kolenda, R.; Schierack, P.; Weinreich, J.; Rödiger, S.; Schierack, J.; Stubbe, M.; Lkhagvasuren, D.; Guenther, S.; Schaufler, K. Investigation of Commensal Escherichia coli Populations of Cormorant Hatchlings in the Absence of Anthropogenic Impacts in Remote Areas of West Mongolia. Microorganisms 2021, 9 , 372. https://doi.org/10.3390/ microorganisms 9020372

Academic Editor: Ana Hurtado

Received: 29 January 2021

Accepted: 10 February 2021

Published: 12 February 2021

Publisher's Note: MDPI stays neutral with regard to jurisdictional claims in published maps and institutional affiliations.

Copyright: (c) 2021 by the authors. Licensee MDPI, Basel, Switzerland. This article is an open access article distributed under the terms and conditions of the Creative Commons Attribution (CC BY) license (https:/ / creativecommons.org/licenses/by/ $4.0 /)$.
7 Pharmaceutical Biology, Institute of Pharmacy, University of Greifswald, 17489 Greifswald, Germany; sebastian.guenther@uni-greifswald.de

8 Pharmaceutical Microbiology, Institute of Pharmacy, University of Greifswald, 17489 Greifswald, Germany

* Correspondence: katharina.schaufler@uni-greifswald.de; Tel.: +49-3834-420-4869

\begin{abstract}
To increase our understanding of bacterial intestinal colonization in animal populations lacking substantial anthropogenic influence we studied the diversity of E. coli in cormorants from the pristine West-Mongolian steppe. E. coli were isolated from individual birds of two cormorant colonies located on small islands in lakes at least $100 \mathrm{~km}$ away from human settlements. Diversity of the isolates was studied using pulsed-field gel electrophoresis (PFGE). 137 isolates of cormorant colony-1 and 75 isolates of cormorant colony-2 resulted in 60 and 33 PFGE types, respectively. Representative strains of each PFGE type were analyzed via PCR in terms of phylogroups and extraintestinal virulence-associated genes (exVAGs). Bacterial adhesion to the chicken intestinal cell line CHIC8E11 and antimicrobial resistance was also determined. Most isolates belonged to phylogroup B1 $(68.3 \%)$ followed by B2 and E with B2 harboring the highest total number of exVAGs per isolate. Unexpectedly, a PFGE type with relatively few exVAGs displayed the highest isolation frequency, also showing a high adhesion rate. Comparative analysis of exVAGs to other E. coli populations of wildlife origin revealed that the secreted autotransporter toxin encoding sat gene was only present in cormorants. Overall, E. coli in cormorants maintained a high diversity under minimal anthropogenic influences, which likely enables intestinal colonization.
\end{abstract}

Keywords: adhesion; antibiotic resistance; commensal; cormorants; E. coli; virulence

\section{Introduction}

Bacterial colonization in animal guts starts early on during birth and in continuous stages until the intestinal microbiome reaches a functional, complex and dynamic ecosystem [1]. Depending on the bacterial strains in such microbiological environments, colonization varies and persists over months or years after a niche was developed whereas others may disappear with time even within weeks [2]. Bacterial colonization can be defined as the indefinite presence of a particular population of bacteria without reintroduction of that particular population. Studies on human fecal samples showed that-despite external and internal pressures—-they are colonized on average by five different E. coli 
strains [3]. In fecal content of pigs raised in the same house, even 34 different E. coli strains were found. Additionally, if five different individuals in a similar environment are taken together, diversity increases as each might have different strains at a particular time showing that intestinal E. coli strains strongly vary between individuals. Diversity is highly dynamic; even in piglets from the same environment [4]. It can be concluded that diversity exists among commensal $E$. coli strains and that they may possess different strategies and physiological properties to colonize and inhabit the intestinal environment [3]. Antibiotic resistance may also confer additional competitive advantages to those strains. Finally, all other factors being equal, the strains that are able to grow and survive in these environments ultimately lead to more success [5].

Escherichia coli is a metabolically versatile bacterium that colonizes the intestines of mammals and birds [6]. Some E. coli strains are pathogenic, causing various intestinal and extraintestinal diseases affecting humans and animals [7]. The species has a variety of virulence-associated factors, which can also be found in healthy hosts rendering colonization advantages such as adhesins, toxins, iron acquisition factors, lipopolysaccharides, polysaccharide capsules and invasins, which are frequently encoded on mobile genetic elements [4]. Commensal E. coli may serve as a relevant and representative model for establishing microbial principles in the intestinal microbiome due to its demonstrative features of the whole microflora [8]. Intestinal E. coli populations are individual, dynamic, and very complex, but are not well understood. Already published studies show factors such as metabolism, microcin production, virulence-associated genes of extraintestinal pathogenic E. coli, antibiotic resistances and other factors facilitate successful bacteria colonization $[2,4,5,9]$. Research on intestinal E. coli strains focusing on diversity, virulence traits, phylogenetic categorization and antibiotic resistance gives vital insights about harboring hosts and the risks for diseases, pathogen transmission, or resistance/endurance to antibiotics [10]. Already published work focused on comparative advantage and/or disadvantage of competitive colonization using mouse models, cell culture models or bioreactors with limited bacterial strains. Additionally, little data is available on the complex dynamics of commensal E. coli populations and their colonization in a natural environment devoid of anthropogenic pressures.

The aim of this study was to observe bacterial intestinal colonization parameters and explore the reasons behind dominance or higher prevalence of particular strains in isolated naturally occurring animal populations in the (mostly) absence of anthropogenic and antibiotic selection pressures. The present study focuses on two separate colonies of Great Cormorant (Phalacrocorax carbo) hatchlings sampled during bird ringing on small islands of $\sim 200 \mathrm{~m}^{2}$ in the middle of two different lakes at least $100 \mathrm{~km}$ away from permanent human settlements in Mongolia and $568 \mathrm{~km}$ from each other. The lakes were in the middle of the semi desert or desert steppe, where livestock was absent, and the lake was the only source of food and water. The islands were densely populated with cormorant nestlings with a distance of less than one meter between nests. Given the close proximity of the birds and the single source of feeding from only one lake and low anthropogenic influences, we would have expected the $E$. coli diversity to be rather low. Although we assume that E. coli harbored by cormorants in remote Mongolia areas are not exposed to antibiotic selection pressure, the animals can ingest and thus harbor antibiotic-resistant E. coli due to bird migration in their winter quarters.

Evaluation of the distribution of phylogenetic groups, prevalence of virulence-associated genes and adhesion rates of $E$. coli isolates as well as determination of the sensitivity to antimicrobials increase our understanding and explore possible reasons for the colonization abilities and diversity of commensal E. coli strains in remote natural environment lacking substantial anthropogenic influences. 


\section{Materials and Methods}

\subsection{Definitions}

Isolates of one PFGE (pulsed-field gel electrophoresis) type did not differ in more than three bands from each other [11]. Extraintestinal virulence-associated genes (exVAGs) are virulence-associated genes which are involved in the E. coli pathogenesis of extraintestinal infections including infections caused by avian pathogenic E. coli (APEC). exVAGs were also shown to support colonization of E. coli in healthy hosts [4].

\subsection{Study Area}

E. coli were sampled on a bird ringing expedition in Mongolia in July 2017 during the Mongolian-German Biological Expedition No. 347, which have been organized since 1962. Cormorant colony-1 was located in the lake Buuntsagaan, Bayankhongor province (N45 ${ }^{\circ}$ E99 ${ }^{\circ}$, Cormorant colony-2 was located the lake Airag, Uvs province (N48 E93.19'19.2' ${ }^{\prime \prime}$ ) as shown in Figure 1. The overall population data for Mongolia are as follows: human density: 1-2 $\mathrm{n} / \mathrm{km}^{2}$, livestock densities: swine $<1 \mathrm{n} / \mathrm{km}^{2}$, cattle $1-5 \mathrm{n} / \mathrm{km}^{2}$, small ruminants $5-10 \mathrm{n} / \mathrm{km}^{2}$, poultry $<10 \mathrm{n} / \mathrm{km}^{2}$. These very low numbers are expected to be even lower in the sampling locations of this study as they are among the least densely human-populated areas in the world and livestock as well as large cities were not present [12].
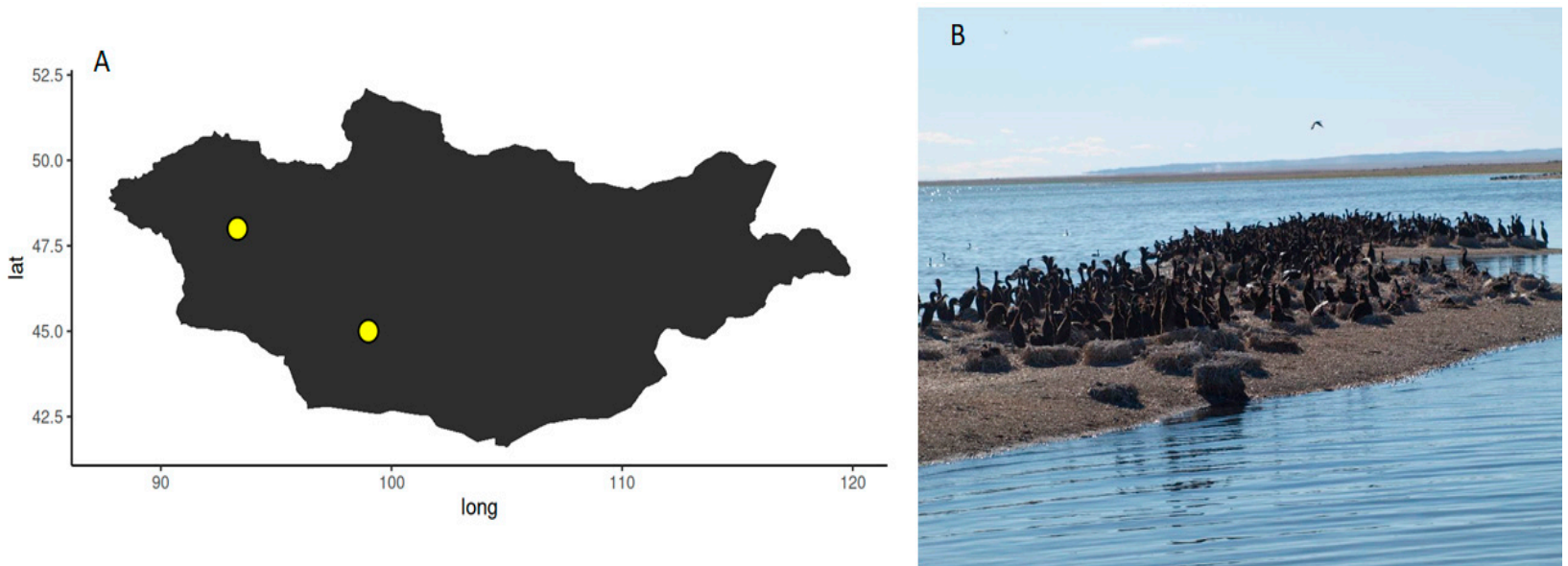

Figure 1. (A) Map of Mongolia depicting the sample locations of E. coli isolates; (B) cormorant colony-1 on an island in the lake Buuntsagaan, Bayankhongor province (N48 E93.19'19.2' $)$.

\subsection{Collection of Bacterial Isolates}

During bird ringing, we sampled hatchlings once and shipped cloacal swabs (MASTASWAB containing Amies Medium with charcoal, Mast Diagnostica GmbH Reinfeld, Germany) to the lab in Senftenberg, Germany. Cloacal swabs were streaked on CHROMagar orientation plates (Mast Diagnostica $\mathrm{GmbH}$, Reinfeld, Germany [13]) and one single pink colored colony from each plate per bird was taken [14,15], and was further confirmed by MALDI-TOF (microflex, Bruker, Billerica, MA, USA). One single E. coli colony was then subcultured twice on CHROMagar orientation plates and stored in $20 \%$ glycerol at $-80{ }^{\circ} \mathrm{C}$ until further processing. All E. coli isolates were categorized by macrorestriction analysis to PFGE types using XbaI restriction digestion as previously described [9].

\subsection{Antimicrobial Susceptibility Testing}

One isolate of each PFGE type from cormorant colony-1 was tested for antimicrobial resistance against 28 substances/combinations (Table S1) by the agar disk diffusion method according to the Clinical and Laboratory Standards Institute (CLSI) [16]. 


\subsection{DNA Preparation, Virulence, and ECoR Genotyping}

One isolate of each PFGE type from cormorant colony-1 was investigated for 30 exVAGs also typical for avian pathogenic E. coli by multiplex PCR as described before $[17,18]$. They were classified according to the E. coli Reference Collection (ECoR) system [19] by use of a PCR previously described [20,21]. Selection of exVAGs, primers (BioTez, Berlin, Germany) and PCR conditions are based on a previous study [17].

\subsection{E. coli Adhesion Assay}

Chicken intestinal cells CHIC-8E11 (MicroMol GmbH, Karlsruhe, Germany) were grown in 96-well plates (Nunc, Langenselbold, Germany) in Dulbecco's modified Eagle Medium (DMEM) HAM'S/F-12 (1:1) (Biochrom, Berlin, Germany), supplemented with $10 \%$ fetal calf serum (Biochrom, Berlin, Germany), 1\% L-Glutamine (Biochrom, Berlin, Germany), and maintained in an atmosphere of $5 \% \mathrm{CO}_{2}$ at $37^{\circ} \mathrm{C}$ [22]. Adhesion assays were performed essentially as previously described [23]. Confluent CHIC-8EII cell monolayers were inoculated with one E. coli isolate of each PFGE type from cormorant colony- 1 with an infection dose of 62,500 bacteria per $\mathrm{mm}^{2}$ of a cell monolayer using a conversion factor of approximately $3 \times 10^{8}$ bacteria $/ \mathrm{mL} / \mathrm{OD}_{600}$. This infection corresponded to a multiplicity of infection (MOI) of 100:1 E. coli to host cells. Cells were incubated with E. coli for $3 \mathrm{~h}$ at $37^{\circ} \mathrm{C}$. A FISH staining method was used for quantification of adherent bacteria on chicken cell line [24]. The plates were washed three times with distilled water. After fixation by formaldehyde (4\%), cells were dehydrated with $50 \mu \mathrm{L}$ of $95 \%$ ethanol for $5 \mathrm{~min}$, dried and stored at $4{ }^{\circ} \mathrm{C}$ until performing FISH. $40 \mu \mathrm{L}$ of FISH probe EUB338 Atto647N with a final concentration of $5 \mathrm{ng} / \mu \mathrm{L}$ was added to each well and the plates were incubated at $46^{\circ} \mathrm{C}$ for $1 \mathrm{~h}$ in a humid chamber [24]. The plates were washed once with a washing buffer and incubated at $48{ }^{\circ} \mathrm{C}$ for $10 \mathrm{~min}$ in the washing buffer. Nuclei were stained with DAPI $(50 \mu \mathrm{g} / \mathrm{mL}$ in distilled water) and washed once with $1 \times$ PBS. Finally, plates were analyzed by the Aklides ${ }^{\circledR}$ system (Medipan GmbH, Potsdam, Germany) $[17,25]$.

We classified bacterial adhesion as: (1) low (1-2000 bacteria/ $\left.\mathrm{mm}^{2}\right)$; (2) medium (2001-4000 bacteria $/ \mathrm{mm}^{2}$ ); and (3) highly adherent (more than 4000 bacteria $/ \mathrm{mm}^{2}$ ). Assays were done in triplicate wells and were repeated at least three times.

\subsection{Statistical Analyses}

Statistical analysis was carried out using the R statistical software [26]. Gene prevalence was compared with the Chi-squared test of independence implemented in the $\mathrm{R}$ package. Figures were generated with the use of ggplot2 package implemented in R software [27]. The data were reordered by hierarchical clustering analysis using complete linkage method and R software [28]. Analysis of gene combinations among the virulence gene pattern of E. coli isolates was performed with Microsoft Office Excel 2003 (Microsoft, Redmond, WA, USA).

\subsection{Ethics Statement}

We carried out the sampling of nestlings in Mongolia during bird ringing and the animals were released afterward in accordance with the Ornithological Council's guidelines on the use of wild birds in research [29]. We conducted sampling in Mongolia with the approval and in cooperation with the National University of Mongolia in Ulaan-Baatar, Mongolia. According to the IUCN Red List of Threatened species, the conservation status of cormorants (Phalacrocorax carbo) of this study was of "least concern" (LC).

\section{Results}

\subsection{Clonal Diversity of E. coli Populations of Two Cormorant Colonies}

As a result, of PFGE typing, out of 137 isolates of cormorant colony- 1 we defined 60 PFGE types. High diversity in terms of PFGE types was exhibited where 43 PFGE types were represented by single isolate per PFGE type. The most prevalent PFGE type of cormorant colony- 1 had 39 isolates. In case of cormorant colony-2 with 75 isolates, 
we defined 33 PFGE types where 22 PFGE types had only one isolate, the maximum was one PFGE type with 11 isolates (Table 1). Due to the fact that the most prevalent PFGE type was present in cormorant colony-1 along with a high diversity, we decided to investigate this colony further in terms of exVAGs prevalence, phylogroups, adhesion rates and antibiotic resistance.

Table 1. Summary of pulsed-field gel electrophoresis (PFGE) types and number of isolates in each type in cormorant colony 1 and 2 .

\begin{tabular}{|c|c|c|c|c|c|c|c|c|c|c|}
\hline $\begin{array}{c}\text { Number of Isolates } \\
\text { Per PFGE Type }\end{array}$ & 1 & 2 & 3 & 4 & 5 & 6 & 7 & 8 & 11 & 39 \\
\hline Cormorant colony-1 & $43 *$ & $9 *$ & 2 & 1 & 0 & 1 & 3 & 0 & 0 & 1 \\
\hline Cormorant colony-2 & 21 & 5 & 1 & 1 & 2 & 0 & 0 & 2 & 1 & 0 \\
\hline
\end{tabular}

* 43 PFGE types had one isolate, 9 PFGE types had two isolates, etc.

\subsection{Virulence-Associated Gene Profiles and Phylogenetic Affiliation}

Different exVAGs have been shown to be intestinal bacterial colonization factors and we screened one strain from each of 60 PFGE types of cormorant colony-1 for 30 exVAGs using PCR (Table 2). Overall, the prevalence of exVAGs was low and differed markedly between different PFGE types. Genes associated with large plasmids, occurred in a substantial number only in the case of traT (60\%), whereas others, including iss $(10 \%)$, sitep $(1.7 \%)$, iut $A(6.7 \%)$, tsh $(1.7 \%)$ and iucD (5\%), yielded a lower prevalence. iroN and cvi/cva were not detected in the entire population of $E$. coli in the cormorant colony-1. Additionally, afa/dra, $h l y A$, papC and $c n f 1 / 2$ were also absent in the whole population, every other exVAG was found in at least one isolate, with fim $\mathrm{C}(100 \%)$ and omp $A(100 \%)$ being the most prevalent and ibeA (5\%), sfa/foc (3.33\%), pic (3.33\%), sitep $(1.67 \%)$, tsh $(1.67 \%)$ and tia $(1.67 \%)$ with the lowest prevalence (Table 2). There were seven isolates with the lowest number of exVAGs in a single isolate, i.e., five exVAGs. Two isolates were found with 13 exVAGs, which is the maximum number in a single isolate.

Each isolate from a single PFGE type was classified into phylogroups according to the ECoR (E. coli Reference Collection) system. Most isolates belonged to the ECoR group B1 (68.3\%) followed by B2 (15\%) and E (6.7\%). Only one isolate belonged to group D and none were identified as ECoR group A. Five isolates could not be assigned to any of the ECoR group due to conflicting information by PCR results. Possible correlations between ECoR groups, virulence-associated genes, and isolation frequencies were also analyzed. On average, ECoR group B2 isolates carried most exVAGs per isolate $(11 \pm 2.0)$, followed by isolates of group B1 $(7.2 \pm 1.8)$ and $\mathrm{E}(6.75 \pm 1.3)$. Isolates grouped as undetermined in ECoR groups carried $7.4 \pm 1.8$ exVAGs per isolate.

\subsection{Adhesion Assays}

Since there is no cormorant cell line available, we used the intestinal chicken cell line CHIC-8E11 and tested one isolate from each PFGE type from cormorant colony- 1 for adhesion. After incubation of three hours with CHIC-8E11 monolayer, adhesion of E. coli varied strongly between ranging from $169 \mathrm{bacteria} / \mathrm{mm}^{2}$ to $10,095 \mathrm{bacteria} / \mathrm{mm}^{2}$. Most PFGE types can be categorized as low colonizers $(n=42)$ with adhesion rates with less than 1000 bacteria $/ \mathrm{mm}^{2}$ followed by medium colonizers, i.e., $2001-4000$ bacteria $/ \mathrm{mm}^{2}$ $(\mathrm{n}=12)$. Six isolates were found to adhere strongly to CHIC-8E11 cells with more than 4000 bacteria $/ \mathrm{mm}^{2}$.

\section{4. exVAG Profiles of E. coli and Relationship between Different Colonization Parameters}

To analyse the association of exVAGs and the ability of intestinal colonization in the intestine of cormorants, we compared the numbers of exVAGs and adhesion rates via cluster analysis (Figure 2). We found no clustering between exVAGs gene prevalence and adherence rates on the chicken cell line that would point toward a correlation of successful colonization of commensal E. coli with the total number of exVAGs present. 
Table 2. Functions and prevalence percentage of detected extraintestinal virulence-associated genes (exVAGs) in E. coli in cormorants, mallard ducks, wild birds, and wild animals. Pearson's Chi-squared test for count data calculated to compare the significant differences in prevalence.

\begin{tabular}{|c|c|c|c|c|c|c|}
\hline Genes & Functions & $\begin{array}{l}\text { Cormorants } \\
n=60\end{array}$ & $\begin{array}{l}\text { Mallard Ducks } \\
\quad n=220\end{array}$ & $\begin{array}{l}\text { Other Wild Birds } \\
\qquad \mathrm{n}=54\end{array}$ & $\begin{array}{c}\text { Total Wild Birds } \\
\mathrm{n}=334\end{array}$ & $\begin{array}{l}\text { Wild Mammals } \\
\qquad \mathbf{n}=187\end{array}$ \\
\hline kpsMTII & Adhesin & 21.7 & 14.4 & $0.0 *$ & 13.2 & $0.0^{*,+}$ \\
\hline$a f a / d r a$ & Adhesin & 0.0 & 0.0 & 0.0 & 0.0 & 0.0 \\
\hline sfa/foc & Adhesin & 3.3 & 9.3 & 9.3 & 8.4 & $2.1^{+}$ \\
\hline pic & Miscellaneous & 3.3 & 9.6 & 14.8 & 9.3 & $14.4 *$ \\
\hline hra & Adhesin & 53.3 & $17.8 *$ & 40.7 & 28.4 & $34.8 *$ \\
\hline$h l y A$ & Toxin & 0.0 & $8.7 *$ & 0.0 & 5.7 & 3.7 \\
\hline$i b e A$ & Invasin & 5.0 & 15.2 & $31.5 *$ & 16.2 & $16.0 *$ \\
\hline $\operatorname{traT}{ }^{\mathrm{a}}$ & Protectin & 60.0 & $41.3 *$ & $38.9 *$ & 44.6 & $41.2 *$ \\
\hline sitchr & Siderophore & 20.0 & $33.4 *$ & 31.5 & 31.7 & $20.3^{+}$ \\
\hline ompA & Protectin & 100.0 & 99.5 & 100.0 & 99.7 & 99.5 \\
\hline $\operatorname{iroN}{ }^{\mathrm{a}}$ & Siderophore & 0.0 & $21.6 *$ & $25.9 *$ & 18.6 & $10.2 *,+$ \\
\hline sitep & Siderophore & 1.7 & $13.2 *$ & 7.4 & 10.2 & $4.3^{+}$ \\
\hline vat & Toxin & 33.3 & 22.9 & 24.1 & 25.1 & $15.5^{*,+}$ \\
\hline$t s h^{\mathrm{a}}$ & Adhesin & 1.7 & 7.0 & $18.5^{*}$ & 8.1 & $3.2^{+}$ \\
\hline$i u c D^{\mathrm{a}}$ & Siderophore & 8.3 & 8.6 & 5.6 & 8.1 & $3.2^{+}$ \\
\hline$c v i / c v a^{\mathrm{a}}$ & Protectin & 0.0 & $13.8 *$ & 1.9 & 9.3 & 4.3 \\
\hline papC & Adhesin & 0.0 & $9.1 *$ & 0.0 & 6.0 & $1.6^{+}$ \\
\hline iss ${ }^{\mathrm{a}}$ & Protectin & 10.0 & 19.7 & 1.9 & 15.3 & $2.1^{*++}$ \\
\hline EAST1 & Toxin & 50.0 & $24.9 *$ & $29.6 *$ & 30.5 & $31.6^{*}$ \\
\hline$c n f 1 / 2$ & Toxin & 0.0 & 7.3 & 0.0 & 4.8 & $0.0^{+}$ \\
\hline iut $A^{\mathrm{a}}$ & Siderophore & 6.7 & 8.9 & 7.4 & 8.4 & $3.2^{+}$ \\
\hline mat & Adhesin & 93.3 & $74.8 *$ & 85.2 & 80.2 & $78.1 *$ \\
\hline fyuA & Siderophore & 23.3 & $37.2 *$ & 40.7 & 35.9 & $20.3^{+}$ \\
\hline sat & Toxin & 13.3 & $0.0 *$ & 0.0 * & 2.4 & $0.0 *$ \\
\hline $\operatorname{malX}$ & Miscellaneous & 33.3 & 22.3 & 25.9 & 25.1 & $17.1^{*,+}$ \\
\hline $\operatorname{csg} A$ & Adhesin & 95.0 & $73.4 *$ & 90.7 & 80.5 & $89.3^{+}$ \\
\hline fimc & Adhesin & 100.0 & 92.7 & 96.3 & 94.6 & 96.8 \\
\hline $\operatorname{irp} 2$ & Siderophore & 31.7 & 34.9 & 33.3 & 34.1 & $20.3^{+}$ \\
\hline ireA & Siderophore & 6.7 & 3.9 & 5.6 & 4.8 & $12.8^{+}$ \\
\hline tia & Invasin & 1.7 & 2.0 & $18.5^{*}$ & 4.8 & $15.0^{*,+}$ \\
\hline $\operatorname{chuA}$ & Siderophore & 23.3 & 46.9 * & $63.0 *$ & 45.8 & $41.7^{*}$ \\
\hline
\end{tabular}

${ }^{a}$ Genes associated with large plasmids, like pAPEC-O2-ColV [NC_007675], pTJ100 [AY553855] and pAPEC-O1-ColBM [DQ381420]; ${ }^{*} p<0.05$ when compared with occurrence percentage in cormorant colony- $1 ;^{+} p<0.05$ when occurrence compared between total birds and wild mammals.

Further analysis and comparisons were drawn to explore the reasons leading to successful colonization of E. coli in the environment devoid of human and antibiotic pressures as shown in Figure 3A-E. Most PFGE types comprising of one to two isolates and exhibiting quite diverse adhesion patterns belonged to phylotype B1 (Figure 3A). Interestingly, the PFGE type with the highest frequency of isolates (39 isolates) was also categorized as B1 and showed a high adhesion rate. Overall, phylogroup B1 displayed the highest number of isolates and exhibited diverse adhesion rates with five, seven and twenty-nine isolates as high, medium, and low adherence to the avian cell line, respectively (Figure 3B). Interestingly, most of the isolates categorized in phylogroup B2 showed low adhesion rates with two exceptions with medium and high adhesion. No conclusion can be drawn for phylogroup $\mathrm{D}$ and $\mathrm{E}$ due to the low number of isolates. No direct positive or negative correlation can be drawn between the presence of exVAGs and the adhesion rate (Figure 3C). The Figure 3C shows that a higher number of exVAGs does not correlate with a high adhesion rate. The isolate with the highest adhesion rate or around 10,000 bacteria per $\mathrm{mm}^{2}$ had only six exVAGs. Whereas the isolates with 12 and 13 exVAGs displayed low adhesion capacities. On average isolates belonging to phylogroup B2 displayed the highest number of exVAGs followed by phylogroup B1, which has a high variation on the average number of exVAGs as presented in Figure 3D. Isolates which could not be categorized in any of the phylogroups labeled as undetermined also show diversity in terms of adhesion rate and number of exVAGs. There is no positive and negative correlation between isolation frequency and the number of exVAGs (Figure 3E). It is worth mentioning that the PFGE 
type with one of the lowest numbers of exVAGs has the highest isolation frequency with 29 isolates along with a high adhesion rate.
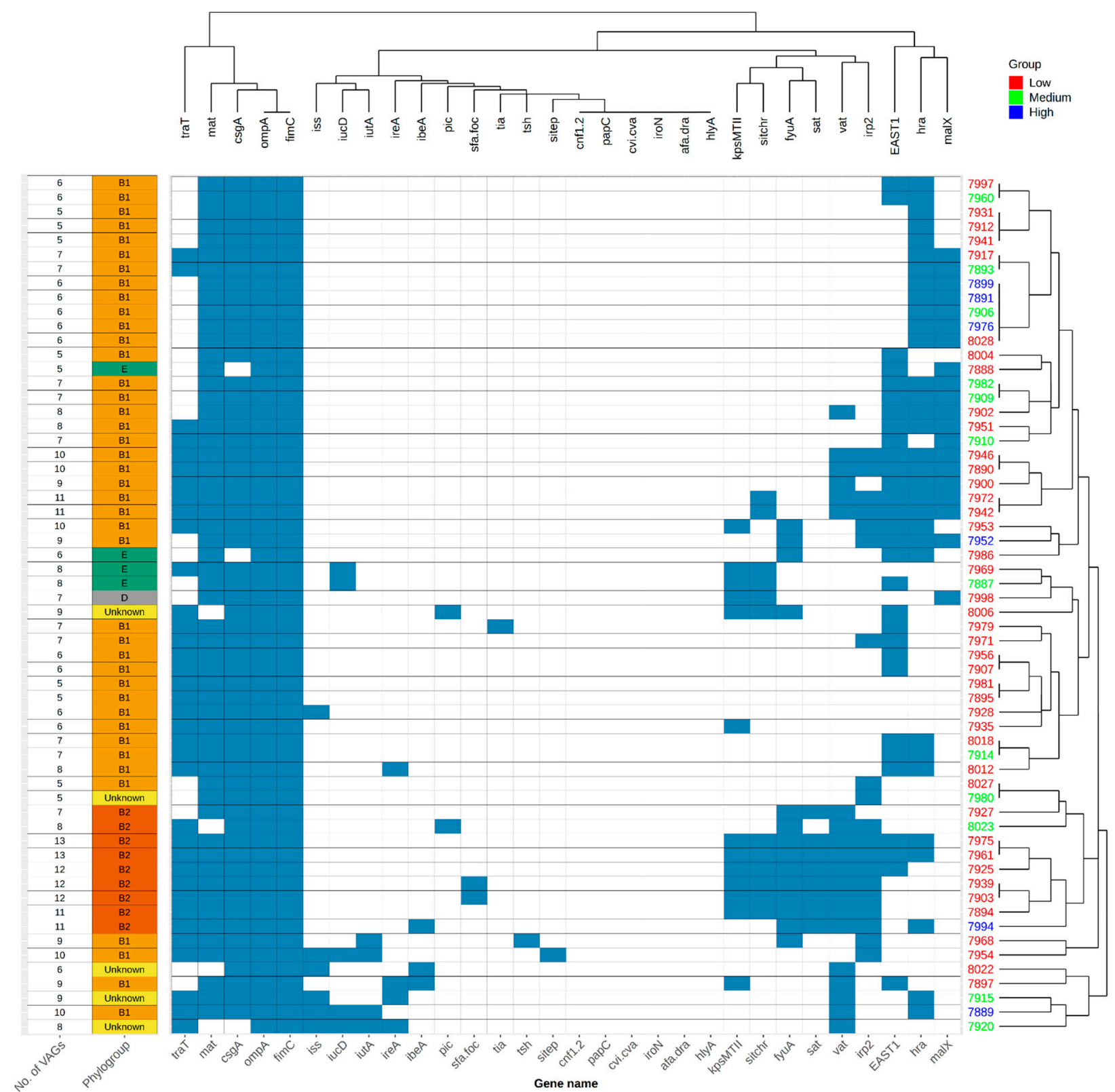

Figure 2. exVAGs profile cluster analysis in association with adhesion rates, phylogroups and number of exVAGs. One strain from each PFGE type was screened for exVAGs, adhesion rates and phylogroup determination.

\subsection{Antimicrobial Susceptibility and Possible Correlations with Adhesion Rates}

Resistance to antimicrobial substances affects colonization of intestinal E. coli $[2,30]$, and we therefore phenotypically tested one isolate of each PFGE type for antimicrobial resistance using agar disk diffusion assays. In cormorant colony-1, most isolates were susceptible to all antimicrobial substances. Resistances were found to amoxicillin (3 isolates) and ampicillin (9 isolates). Interestingly, one isolate was resistant to seven different substances/combinations, i.e., ampicillin, amoxicillin-clavulanic acid, ampicillin-sulbactam, doxycycline, tetracycline, ticarcillin and trimethoprim. 

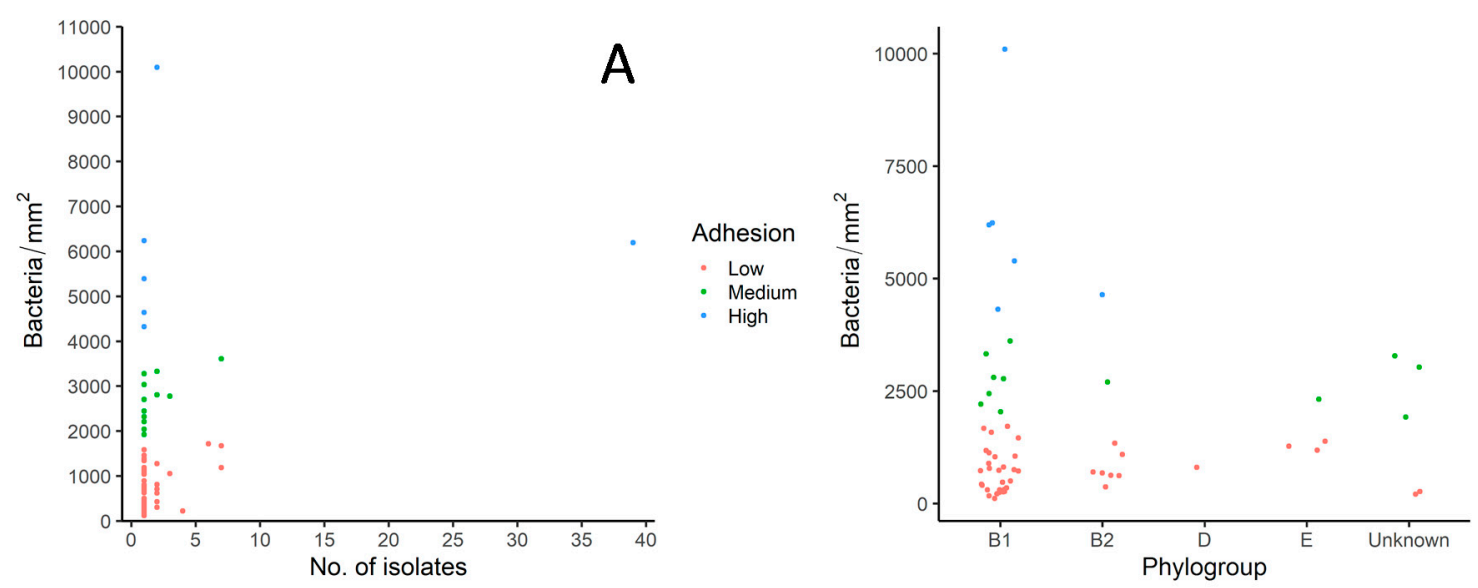

B
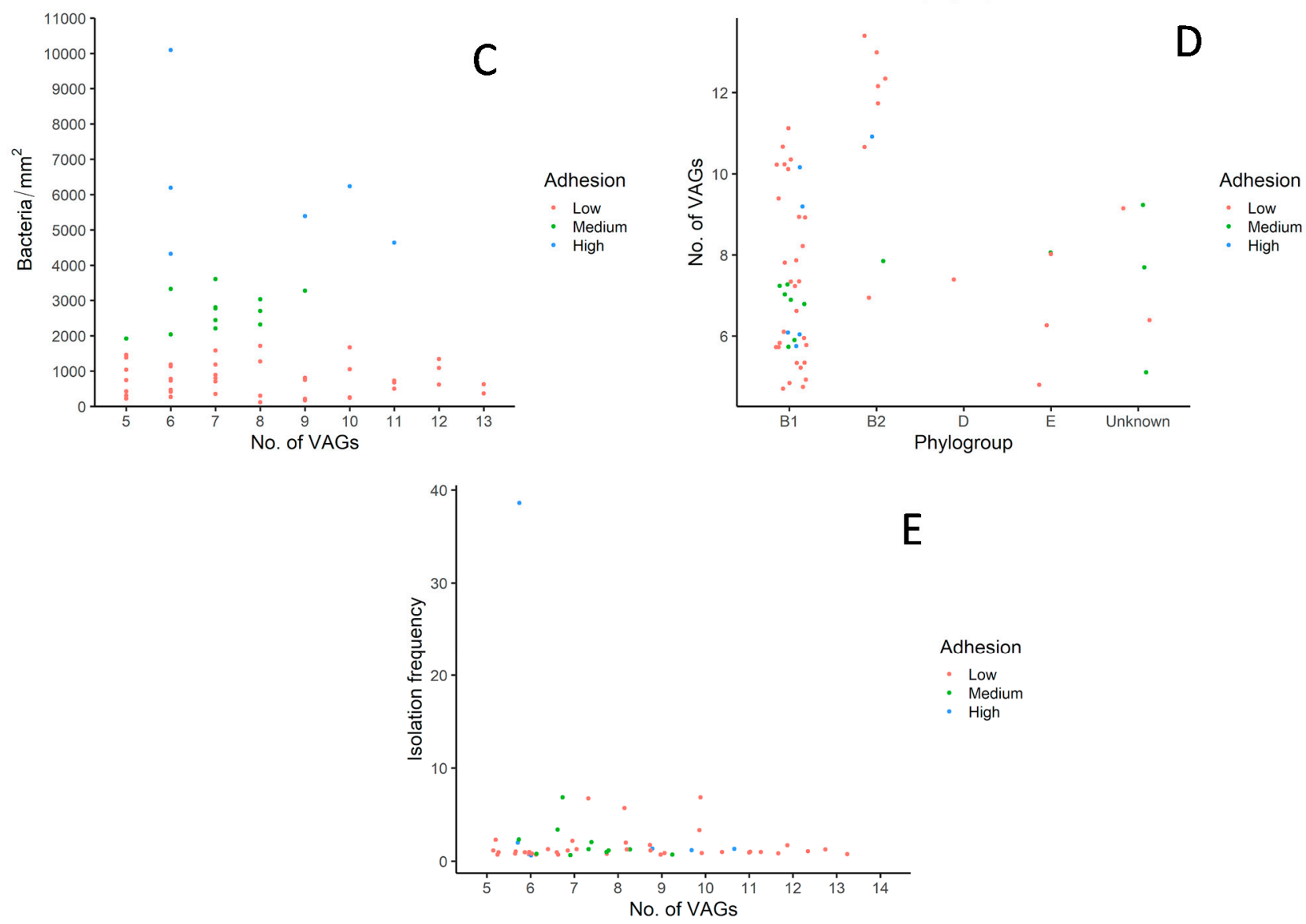

Figure 3. Correlation analysis for colonization parameters of E. coli in cormorant colony-1. (A) Number of isolates per pulsotype with adhesion rates; (B) Phylogroups with adhesion rates; (C) Adhesion rates with number of exVAGs; (D) Phylogroups with number of exVAGs; (E) Number of exVAGs with isolation frequency. Shown are scatterplots with one plot representing one pulsotype.

Since resistance prevalence was low in the commensal E. coli population in this remote area of Mongolia, most of the diverse adherence patterns are observed in isolates with almost no resistance to any of the antibiotics as shown in Figure 4A. The strain which was resistant to seven different antibiotics had a very low adherence rate. In the absence of antibiotic pressure, a significant number of isolates had intermediate resistance (according to CLSI document M100-S23 (M02-A11)) to a diverse group of antibiotics (Figure 4B). Most of the isolates with medium adhesion rates showed intermediate resistance to relatively low numbers of antibiotics. Maximum diversity in terms of adhesion rates was observed in isolates which had intermediary resistance against up to three antibiotics. Overall down- 
ward trends in adhesion rates with respect to increased sensitivity against the antibiotics is observed (Figure 4C). Isolates, which tested sensitive to almost all of the 28 antibiotics exhibited low adhesion rates as well.
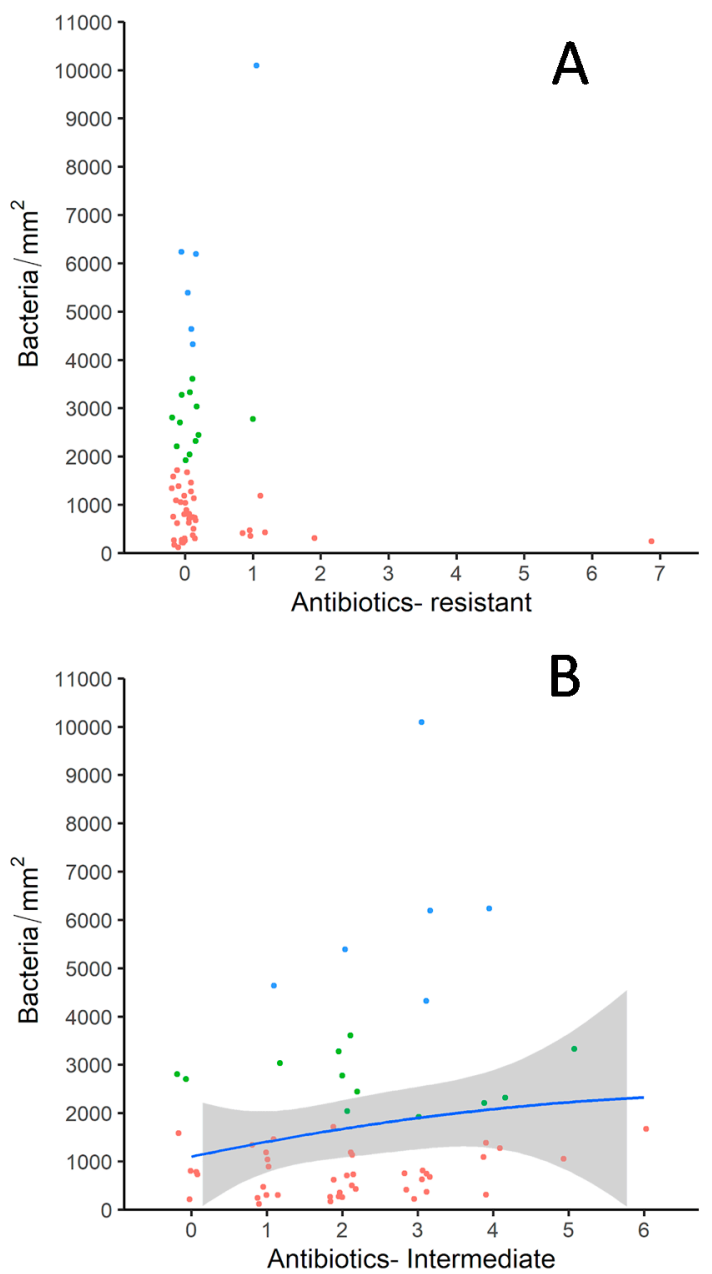

Adhesion

- Low

- Medium

- High

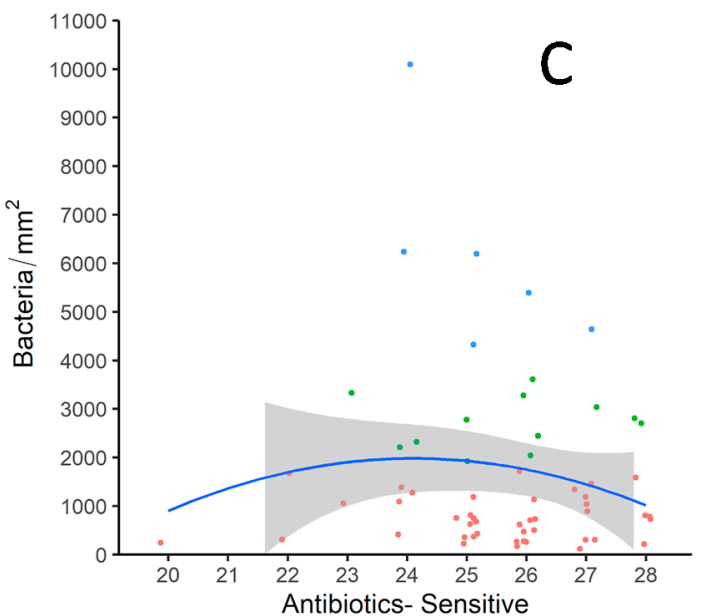

Adhesion

Low

Medium

High

Figure 4. Correlations drawn between antimicrobial susceptibility and adhesion rates of E. coli in cormorant colony-1. (A) Antimicrobial resistance with adhesion rates; (B) Intermediary antimicrobial resistance with adhesion rates; (C) Antibiotic sensitivity with adhesion rates. Shown are scatterplots with one plot representing one pulsotype. 


\section{Discussion}

In contrast to previous works, we studied a bacterial gut population in a pristine animal population originating from an environment with low anthropogenic impact. In this study, we determined the occurrence of intestinal E. coli pulsotypes, explored reasons for higher prevalence and the possible correlations between specific bacterial genes with colonization successes of the respective pulsotypes. Diversity, virulence gene profiles, phylogenetic analysis, and antimicrobial resistance provide important information about intestinal E. coli populations and possible correlations to bacterial colonization, persistence and survival as well as health, diseases, and disease treatment strategies [9].

Surprisingly, the E. coli population was very diverse with up to 60 PFGE types out of 137 isolates of cormorant colony- 1 and 33 PFGE types out of 74 isolates from cormorant colony-2. This high diversity was unexpected due to very similar environmental conditions with food from the same source and densely populated bird colonies located on islands. A high diversity within an E. coli population seems to be a basic natural phenomenon with possible frequent transmission of clones between individuals [14].

Pearson's Chi-squared test for count data was carried out to compare the significant prevalence of exVAGs in E. coli in cormorants and different hosts and environments i.e., mallard ducks, wild birds and wild mammals from already published studies as shown in Table $2[2,17]$. The same statistical analysis was also carried out to compare significant exVAGs prevalence across the two classes, i.e., birds and mammals.

Secreted autotransporter toxin coding sat gene $(p<0.05)$ was absent in E. coli of all the other animals except cormorants of Mongolia. The sat gene is highly prevalent in Uropathogenic (UPEC) and Diffuse-adhering (DAEC) E. coli but its role in infections is dependent on genetic determinants of bacterial pathotypes [31]. The presence of this gene in cormorants of Mongolia indicates such as E. coli Nissle $1917(\mathrm{EcN})$ that some of the E. coli from Mongolia might be closely related to Uropathogeic E. coli [31]. The prevalence of toxin encoding gene east 1 and protectin encoding traT was significantly higher $(p<0.05)$ in cormorants only when compared to studies of mallard ducks and other wild birds. In contrast, other genes such as $h l y A$, cvi/cva, cnf1/2 and papC were absent in E. coli from cormorants and other wild birds but had a higher prevalence in mallard ducks. Three iron acquisition genes such as iroN, sitep and chuA are significantly less prevalent $(p<0.05)$ in cormorant colony- 1 when compared to E. coli populations in other three wildlife populations. When comparing the prevalence of exVAGs in mammals in comparison to wild birds, genes such as kpsMTII, sfa/foc, sitchr, iroN, vat, tsh, iucD, papC, iss, iut $A$, fyuA, malX, irp 2 and chuA were significantly less prevalent in mammals. Only three genes—csgA, ire $A$ and tia-were present more often in mammals.

Phylotyping according to the ECoR system provides a simple tool that allows estimation of pathogenic features of E. coli. It has been proposed that the phylogenetic affiliation indicates a specific type/pathotype of E. coli [20,32,33]. Phylogenetically, E. coli are assigned to seven major phylogenetic groups, namely A, B1, B2, C, D, E and F [21]. Usually, extraintestinal pathogenic strains belong to groups $\mathrm{B} 2$ and $\mathrm{D}$, while isolates belonging to groups A and B1 are more often strictly commensal strains from human intestinal microbiota $[20,21,34]$. Contrary to our present study, where group B1 was mostly isolated in cormorants, most isolated E. coli in mallard ducks were found to belong to group B2 followed by B1 [2]. However, strains from group $E$ and $D$ were found in very low percentages in mallard ducks, which is in line with our study. However, as we used cloacal swabs for this study this might have influenced the outcome of phylotyping and in fecal samples the diversity of $E$. coli might be even higher.

Several studies showed that human and animal extraintestinal pathogenic E. coli from groups B2 and D harbored a greater frequency and diversity of virulence traits compared with strains of other phylotypes [33,35], which is in line with our study regarding B2 with most exVAGs per isolate $(11 \pm 2.0)$.

Adhesion to host epithelial cells is a well-accepted colonization factor [17]. In our study, most strains' adhesion rates ranged from low to medium and there was no significant 
correlation between adhesion and the total number of exVAGs. We conclude that other factors mainly affect colonization in cormorants as underlined by the fact that the PFGE type with the highest isolation frequency [29 isolates] also showed the lowest number of exVAGs but displayed a high adhesion rate. Similarly, a higher number of exVAGs does not correlate with a high adhesion rate and it could be based on the right combination of exVAGs and other factors. The isolate with the highest adhesion rate or around 10,000 bacteria per $\mathrm{mm}^{2}$ had only six exVAGs. However, due to the lack of a cormorant bird intestinal cell line, we chose one of the avian cell lines for the definition of $E$. coli adhesion. It is possible that adhesion patterns may be different with the cormorant intestinal cell line [2].

Emergence and persistence of antimicrobial resistance in a natural environment over decades, independent of any further direct human influence and presence of antimicrobial substances is of scientific and social concern $[2,10,15]$. Conclusively, resistant E. coli were not significantly advantaged or disadvantaged in competition with susceptible $E$. coli and resistance to more agents was not detrimental in comparison to single resistant $E$. coli in the context of their colonization abilities. This might help to understand the occurrence of resistant bacteria in animal populations over long time periods and might substantiate the potential risk of the application of antimicrobial substances in the animal production [10]. Since we sampled hatchlings it was obvious that resistant E. coli were transmitted from adults to the next generation of animals thus showing substantial colonization capabilities of resistant E. coli without substantial environmental influences in Mongolia. The migratory route for these cormorants is unknown however it was shown for other birds that they migrate to India or neighboring southern countries [36]. We assume that cormorants have similar southward migration routes, at least during the harsh winters of Mongolia.

\section{Conclusions}

In conclusion, the E. coli populations of great cormorant hatchlings were highly diverse even in the absence of external anthropogenic pressures. As we used cloacal swabs for this study, their diversity might be even higher in fecal samples. We hypothesize that many strains can coexist even in a very homogeneous environment.

Supplementary Materials: The following are available online at https:/ / www.mdpi.com/2076-260 7/9/2/372/s1, Table S1: Antimicrobial susceptibility testing of E. coli isolated from cormorants.

Author Contributions: P.S., M.M.K., K.S. and S.G. conceived and designed the experiments. P.S., S.G., J.S., M.S. and D.L. collected the data and samples. M.M.K., J.W. and P.S. performed laboratory analysis. M.M.K., P.S., R.K., S.G., S.R. and K.S. analyzed the data and wrote the manuscript. All authors have read and approved the final draft of the manuscript.

Funding: This work was supported by InnoProfile-Transfer 03IP611, 03IPT611A and 03IPT611X funded by the Federal Ministry of Education and Research (BMBF, Germany).

Institutional Review Board Statement: Not applicable.

Informed Consent Statement: Not applicable.

Data Availability Statement: The data presented in this study is available in the manuscript and its Supplementary Material.

Conflicts of Interest: The authors declare no conflict of interest. The funders had no role in the design of the study; in the collection, analyses, or interpretation of data; in the writing of the manuscript, or in the decision to publish the results.

\section{References}

1. Huffnagle, G.B. The Microbiota and Allergies/Asthma. PLoS Pathog. 2010, 6, e1000549. [CrossRef]

2. Rödiger, S.; Kramer, T.; Frömmel, U.; Weinreich, J.; Roggenbuck, D.; Guenther, S.; Schaufler, K.; Schröder, C.; Schierack, P. Intestinal E. Coli Colonization in a Mallard Duck Population over Four Consecutive Winter Seasons. Environ. Microbiol. 2015, 17, 3352-3361. [CrossRef] [PubMed]

3. Conway, T.; Cohen, P.S. Commensal and Pathogenic E. Coli Metabolism in the Gut. Microbiol. Spectr. 2015, 3. [CrossRef] 
4. Schierack, P.; Walk, N.; Ewers, C.; Wilking, H.; Steinrück, H.; Filter, M.; Wieler, L.H. ExPEC-Typical Virulence-Associated Genes Correlate with Successful Colonization by Intestinal E. Coli in a Small Piglet Group. Environ. Microbiol. 2008, 10, $1742-1751$. [CrossRef] [PubMed]

5. $\quad$ Durso, L.M.; Smith, D.; Hutkins, R.W. Measurements of Fitness and Competition in Commensal E. Coli O157:H7 Strains. Appl. Environ. Microbiol. 2004, 70, 6466-6472. [CrossRef] [PubMed]

6. Kaper, J.B.; Nataro, J.P.; Mobley, H.L.T. Pathogenic E. Coli. Nat. Rev. Microbiol. 2004, 2, 123-140. [CrossRef]

7. Bélanger, L.; Garenaux, A.; Harel, J.; Boulianne, M.; Nadeau, E.; Dozois, C.M. E. Coli from Animal Reservoirs as a Potential Source of Human Extraintestinal Pathogenic E. Coli. FEMS Immunol. Med. Microbiol. 2011, 62, 1-10. [CrossRef]

8. Tannock, G.W. Molecular Assessment of Intestinal Microflora. Am. J. Clin. Nutr. 2001, 73, 410s-414s. [CrossRef]

9. Schierack, P.; Römer, A.; Jores, J.; Kaspar, H.; Guenther, S.; Filter, M.; Eichberg, J.; Wieler, L.H. Isolation and Characterization of Intestinal E. Coli Clones from Wild Boars in Germany. Appl. Environ. Microbiol. 2009, 75, 695-702. [CrossRef]

10. Schierack, P.; Kadlec, K.; Guenther, S.; Filter, M.; Schwarz, S.; Ewers, C.; Wieler, L.H. Antimicrobial Resistances Do Not Affect Colonization Parameters of Intestinal E. Coli in a Small Piglet Group. Gut Pathog. 2009, 1, 18. [CrossRef]

11. Tenover, F.C.; Arbeit, R.D.; Goering, R.V.; Mickelsen, P.A.; Murray, B.E.; Persing, D.H.; Swaminathan, B. Interpreting Chromosomal DNA Restriction Patterns Produced by Pulsed-Field Gel Electrophoresis: Criteria for Bacterial Strain Typing. J. Clin. Microbiol. 1995, 33, 2233-2239. [CrossRef]

12. Guenther, S.; Semmler, T.; Stubbe, A.; Stubbe, M.; Wieler, L.H.; Schaufler, K. Chromosomally Encoded ESBL Genes in E. Coli of ST38 from Mongolian Wild Birds. J. Antimicrob. Chemother. 2017, 72, 1310-1313. [CrossRef] [PubMed]

13. Merlino, J.; Siarakas, S.; Robertson, G.J.; Funnell, G.R.; Gottlieb, T.; Bradbury, R. Evaluation of CHROMagar Orientation for Differentiation and Presumptive Identification of Gram-Negative Bacilli and Enterococcus Species. J. Clin. Microbiol. 1996, 34, 1788-1793. [CrossRef] [PubMed]

14. Ewers, C.; Guenther, S.; Wieler, L.H.; Schierack, P. Mallard Ducks-A Waterfowl Species with High Risk of Distributing E. Coli Pathogenic for Humans. Environ. Microbiol. Rep. 2009, 1, 510-517. [CrossRef]

15. Guenther, S.; Filter, M.; Tedin, K.; Szabo, I.; Wieler, L.H.; Nöckler, K.; Walk, N.; Schierack, P. Enterobacteriaceae Populations during Experimental Salmonella Infection in Pigs. Vet. Microbiol. 2010, 142, 352-360. [CrossRef] [PubMed]

16. Watts, J.L.; Shryock, T.R.; Apley, M.; Brown, S.D.; Gray, J.T.; Heine, H.; Hunter, R.P.; Mevius, D.J.; Paich, M.G.; Silley, P. Performance Standards for Antimicrobial Disk and Dilution Susceptibility Tests for Bacteria Isolated from Animals; Approved Standard-Third Edition; Clinical and Labaratory Standards Institute: Annapolis, MD, USA, 2008.

17. Frömmel, U.; Lehmann, W.; Rödiger, S.; Böhm, A.; Nitschke, J.; Weinreich, J.; Groß, J.; Roggenbuck, D.; Zinke, O.; Ansorge, H.; et al. Adhesion of Human and Animal E. Coli Strains in Association with Their Virulence-Associated Genes and Phylogenetic Origins. Appl. Environ. Microbiol. 2013, 79, 5814-5829. [CrossRef] [PubMed]

18. Rödiger, S.; Schierack, P.; Böhm, A.; Nitschke, J.; Berger, I.; Frömmel, U.; Schmidt, C.; Ruhland, M.; Schimke, I.; Roggenbuck, D.; et al. A Highly Versatile Microscope Imaging Technology Platform for the Multiplex Real-Time Detection of Biomolecules and Autoimmune Antibodies. In Molecular Diagnostics; Seitz, H., Schumacher, S., Eds.; Springer: Berlin/Heidelberg, Germany, 2013; pp. 35-74. ISBN 9783642376917.

19. Herzer, P.J.; Inouye, S.; Inouye, M.; Whittam, T.S. Phylogenetic Distribution of Branched RNA-Linked Multicopy Single-Stranded DNA among Natural Isolates of E. Coli. J. Bacteriol. 1990, 172, 6175-6181. [CrossRef] [PubMed]

20. Clermont, O.; Bonacorsi, S.; Bingen, E. Rapid and Simple Determination of the E. Coli Phylogenetic Group. Appl. Environ. Microbiol. 2000, 66, 4555-4558. [CrossRef] [PubMed]

21. Clermont, O.; Christenson, J.K.; Denamur, E.; Gordon, D.M. The Clermont E. Coli Phylo-typing Method Revisited: Improvement of Specificity and Detection of New Phylo-groups. Available online: https://sfamjournals.onlinelibrary.wiley.com/doi/abs/10.1 111/1758-2229.12019 (accessed on 22 January 2021).

22. Ali, A.; Kolenda, R.; Khan, M.M.; Weinreich, J.; Li, G.; Wieler, L.H.; Tedin, K.; Roggenbuck, D.; Schierack, P. Novel Avian Pathogenic E. Coli Genes Responsible for Adhesion to Chicken and Human Cell Lines. Appl. Environ. Microbiol. 2020, 86, e01068-20. [CrossRef]

23. Schierack, P.; Kleta, S.; Tedin, K.; Babila, J.T.; Oswald, S.; Oelschlaeger, T.A.; Hiemann, R.; Paetzold, S.; Wieler, L.H. E. Coli Nissle 1917 Affects Salmonella Adhesion to Porcine Intestinal Epithelial Cells. PLoS ONE 2011, 6, e14712. [CrossRef]

24. Kolenda, R.; Burdukiewicz, M.; Schiebel, J.; Rödiger, S.; Sauer, L.; Szabo, I.; Orłowska, A.; Weinreich, J.; Nitschke, J.; Böhm, A.; et al. Adhesion of Salmonella to Pancreatic Secretory Granule Membrane Major Glycoprotein GP2 of Human and Porcine Origin Depends on FimH Sequence Variation. Front. Microbiol. 2018, 9, 1905. [CrossRef] [PubMed]

25. Willitzki, A.; Hiemann, R.; Peters, V.; Sack, U.; Schierack, P.; Rödiger, S.; Anderer, U.; Conrad, K.; Bogdanos, D.P.; Reinhold, D.; et al. New Platform Technology for Comprehensive Serological Diagnostics of Autoimmune Diseases. Clin. Dev. Immunol. 2012, 2012, 284740. [CrossRef] [PubMed]

26. R Core Team. A Language and Environment of Statistical Computing; R Foundation for Statistical Computing: Vienna, Austria, 2020.

27. Wickham, H. Ggplot2: Elegant Graphics for Data Analysis; Springer: Berlin/Heidelberg, Germany, 2016 ; ISBN 3319242776.

28. Großwendt, A.; Röglin, H. Improved Analysis of Complete-Linkage Clustering; Springer: Berlin/Heidelberg, Germany, 2015 ; pp. 656-667.

29. Fair, J.M.; Paul, E.; Jones, J. Guidelines to the Use of Wild Birds in Research; Ornithological Council: Washington, DC, USA, 2010.

30. Schrag, S.J.; Perrot, V.; Levin, B.R. Adaptation to the Fitness Costs of Antibiotic Resistance in E. Coli. Proc. Biol. Sci. 1997, 264, 1287-1291. [CrossRef] [PubMed] 
31. Toloza, L.; Giménez, R.; Fábrega, M.J.; Alvarez, C.S.; Aguilera, L.; Cañas, M.A.; Martín-Venegas, R.; Badia, J.; Baldomà, L. The Secreted Autotransporter Toxin (Sat) Does Not Act as a Virulence Factor in the Probiotic E. Coli Strain Nissle 1917. BMC Microbiol. 2015, 15, 250. [CrossRef]

32. Bingen-Bidois, M.; Clermont, O.; Bonacorsi, S.; Terki, M.; Brahimi, N.; Loukil, C.; Barraud, D.; Bingen, E. Phylogenetic Analysis and Prevalence of Urosepsis Strains of E. Coli Bearing Pathogenicity Island-like Domains. Infect. Immun. 2002, 70, 3216-3226. [CrossRef] [PubMed]

33. Ewers, C.; Li, G.; Wilking, H.; Kießling, S.; Alt, K.; Antáo, E.-M.; Laturnus, C.; Diehl, I.; Glodde, S.; Homeier, T.; et al. Avian Pathogenic, Uropathogenic, and Newborn Meningitis-Causing E. Coli: How Closely Related Are They? Int. J. Med. Microbiol. 2007, 297, 163-176. [CrossRef]

34. Kuczkowski, M.; Krawiec, M.; Voslamber, B.; Książczyk, M.; Płoskońska-Bugla, G.; Wieliczko, A. Virulence Genes and the Antimicrobial Susceptibility of E. Coli, Isolated from Wild Waterbirds, in the Netherlands and Poland. Vector-Borne Zoonotic Dis. 2016, 16, 528-536. [CrossRef]

35. Le Gall, T.; Clermont, O.; Gouriou, S.; Picard, B.; Nassif, X.; Denamur, E.; Tenaillon, O. Extraintestinal Virulence Is a Coincidental By-Product of Commensalism in B2 Phylogenetic Group E. Coli Strains. Mol. Biol. Evol. 2007, 24, 2373-2384. [CrossRef]

36. Guenther, S.; Aschenbrenner, K.; Stamm, I.; Bethe, A.; Semmler, T.; Stubbe, A.; Stubbe, M.; Batsajkhan, N.; Glupczynski, Y.; Wieler, L.H.; et al. Comparable High Rates of Extended-Spectrum-Beta-Lactamase-Producing E. Coli in Birds of Prey from Germany and Mongolia. PLoS ONE 2012, 7, e53039. [CrossRef] 